\title{
Expression of the full-length and alternatively spliced equine luteinizing hormone/chorionic gonadotropin receptor mRNAs in the primary corpus luteum and fetal gonads during pregnancy
}

\author{
Marie Saint-Dizier, Maryse Chopineau, Joëlle Dupont and Yves Combarnous \\ Unité de Physiologie de la Reproduction et des Comportements, UMR 6175 INRA-CNRS-Université F. Rabelais de \\ Tours-Haras Nationaux, 37380 Nouzilly, France \\ Correspondence should be addressed to Marie Saint-Dizier, Equipe Hypophyse, Station Physiologie de la Reproduction et du \\ Comportement, Institut National de la Recherche Agronomique (INRA), 37380 Nouzilly, France; Email: dizier@tours.inra.fr
}

\begin{abstract}
The full-length equine luteinizing hormone/chorionic gonadotropin (LH/CG) receptor (eLH/CG- $\mathrm{R}_{\mathrm{A}}$ ) cDNA and two alternatively spliced isoforms (eLH/CG- $\left.\mathrm{R}_{\mathrm{B}, \mathrm{C}}\right)$ were isolated from luteal tissue and characterized using a combination of reverse transcription-polymerase chain reaction (RT-PCR) and $5^{\prime}$-rapid amplification of cDNA ends. The 680-amino acid full sequence of eLH/CG- $R_{A}$ displayed 87-92\% homology with other mammalian LH/CG-Rs. The eLH/CG- $R_{B}$ and eLH/CG- $R_{C}$ CDNA isoforms were truncated from the 3 -end of exon $X$ : eLH/CG- $R_{B}$ spliced out of frame into the last exon whereas eLH/CG- $R_{C}$ contained an in-frame stop codon within a divergent sequence. Consequently, both eLH/CG- $R_{B}$ and eLH/CG-R $C$ CDA isoforms encoded putative proteins without transmembrane and intracellular domains.

In order to study the responsiveness of the primary corpus luteum $(\mathrm{CL})$ and fetal gonads to eCG, the expression of eLH/CG-R mRNAs was examined by RT-PCR and Northern blot analysis during early and mid-pregnancy. All three eLH/CG-R cDNA isoforms (eLH/CG- $R_{A, B, C}$ ) were expressed from day 14 to day 83 of pregnancy in the primary $C L$ and from day 44 to day 222 in fetal gonads. Interestingly, the primary $C L$ at days 89 and 151 expressed only truncated eLH/CG-R cDNA isoforms. The relative values of Northern hybridized major 7, 5.7, 3.9 and $1.8 \mathrm{~kb}$ eLH/CG-R mRNA transcripts tended to decrease in the primary CL whereas the unique major $1.8 \mathrm{~kb}$ eLH/CG-R mRNA was steadily expressed in fetal gonads during pregnancy. These results show that the expression of eLH/CG-R mRNAs occurs in the fetal gonads before ceasing in the primary CL and suggest that eCG may be involved in the gradual transition from a luteal to a feto-placental output of steroids during equine pregnancy. Reproduction (2004) 128 219-228
\end{abstract}

\section{Introduction}

In the mare, luteal and feto-placental steroids are successively necessary to maintain pregnancy. Initially, stimulation of the primary corpus luteum $(\mathrm{CL})$ or $\mathrm{CL}$ of conception by pituitary luteinizing hormone $(\mathrm{LH})$ results in a transient increase in the progesterone level, similar to that which occurs during the estrous cycle (Ginther 1992a). From day 35 of pregnancy, coincident with the secretion of the fetal hormone equine chorionic gonadotropin (eCG), the primary $\mathrm{CL}$ increases in size and secretes increasing levels of progesterone and newly synthesized estrogens (Bergfelt et al. 1989, Daels et al. 1991). Thereafter, from day 40 to day 160-180 of gestation, the primary $\mathrm{CL}$ is maintained and continues to secrete progesterone and estrogens (Squires et al. 1974). The fetal gonads, on the other hand, enlarge slowly until approximately day 100 post-ovulation, then very rapidly between days 100 and 200 of gestation, exceeding the weight of maternal ovaries around day 150 of pregnancy (Ginther $1992 b$ ). From days 60 to 80, the fetal gonads in both sexes provide precursor steroids for the placental synthesis of estrone and equine-specific estrogens, equine and equilenin, and contribute to the production of large amounts of estrogens by the feto-placental unit until the end of pregnancy (Pashen \& Allen 1979, Raeside et al. 1979). The equine placenta also produces progesterone and $5 \alpha$-reduced metabolites starting around day 70 , but using maternal sources of cholesterol (Pashen \& Allen 1979). Thus, a gradual transition from a luteal to a feto-placental output of steroids occurs, after which the maternal ovaries 
become small and completely inactive for the remainder of gestation (Holtan et al. 1979). There is convincing evidence that eCG is responsible for the resurgence and support of the primary $\mathrm{CL}$ during early pregnancy in the mare (Urwin \& Allen 1982, Bergfelt et al. 1989, Daels et al. 1998). Furthermore, the primary CL has been shown to be responsive to eCG during the time of eCG secretion (Saint-Dizier et al. 2003). However, whether or not eCG plays a role in the initial development and steroid production of fetal gonads remains unknown.

In pregnant mares and pony mares, the fetal hormone eCG, secreted by the endometrial cups, is first detectable in plasma on days 35-40 of gestation, rises rapidly to reach a peak between days 55 and 70, then decreases slowly to low or undetectable levels by days 120 to 150 of pregnancy (Ginther 1992a, Squires 1993). Whereas the endometrial cups act mainly as endocrine glands in the early stages of cup development, they also act from day 42 as exocrine glands since considerable amounts of eCG pour out of the uterine glands into the space between the cups and the allantochorion (Ginther 1992a). The large amounts of eCG secreted into the uterine lumen raise the possibility that this hormone enters the feto-placental circulation and stimulates the initial hypertropy and steroidogenesis of fetal gonads between days 60 and 120-150 of pregnancy. Nevertheless, it is still unknown whether the fetal gonads are responsive to eCG or to fetal pituitary $\mathrm{LH}$, if present.

The protein structure of eCG is fully identical to that of equine LH (Bousfield et al. 1996) and both hormones bind to the putative LH/CG receptor in equine tissues (eLH/CG-R) (Stewart \& Allen 1979, 1981, Guillou \& Combarnous 1983). We have previously reported the presence of several eLH/CG-R mRNA transcripts in the primary CL by Northern blot (Saint-Dizier et al. 2003). Some of this diversity in transcript size seemed to be due to differences in mRNA sequence since a probe for the transmembrane domain only hybridized to a subset of these transcripts. However, the differences in eLH/CG-R mRNA splicing involved in this process remain unknown. Thus, the aims of this study were first to clone and sequence the full-length eLH/CG-R CDNA and secondly to examine the expression of eLH/CG-R mRNAs in the primary $C L$ and in fetal gonads during early and mid-pregnancy.

\section{Materials and Methods}

\section{Animals}

Light breed mares and Welsh pony-mares ( $3-17$ years old) with no known reproductive pathology were used in this study. Mares were maintained on pasture and supplemented with hay, minerals, and water available ad libitum. The reproductive tracts of the mares were monitored daily during estrus and every other day from ovulation until CL collection using palpation and rectal ultrasonography. The day of ovulation was designated as day 0 of pregnancy. Mares were fertilized by artificial insemination.

\section{Sample collection and RNA isolation}

Luteal tissues were obtained from one cyclic mare in dioestrus as control (day 8 post-ovulation) and from pregnant mares before the onset of eCG secretion (days 14 , $15,26,27,28$ and $31 ; n=1$ for each day), during eCG secretion (days 42, 43, 44, 45, 46, 56, 60, 61, 62, 83 and 89; $n=1$ for each day) and after the end of eCG secretion (day $151, n=1$ ). The ovaries were collected by hemiovariectomy or within 10 min following sodium pentobarbitalinduced euthanasia as previously described (Saint-Dizier et al. 2003). Fetal gonads (both males and females) were collected following induced euthanasia or slaughter of the pregnant mares. The fetal gonads were obtained during eCG secretion (days 44, 45, 47, 62, 70, 81 and 101; $n=1$ for each day) and after the end of eCG secretion (days 151, 202 and 222; $n=1$ for each day). After dissection, pieces of tissue were immediately snap-frozen in liquid nitrogen then stored at $-70^{\circ} \mathrm{C}$.

Total RNA was extracted from fragments of frozen tissue using Trizol reagent (Invitrogen Life Technologies, Gaithersburg, MD, USA) according to the manufacturer's instructions. The resulting RNA was quantified spectrophotometrically, aliquoted into smaller volumes, and stored at $-80^{\circ} \mathrm{C}$.

\section{Isolation and characterization of eLH/CG-R CDNA isoforms}

Total cellular RNA $(2 \mu \mathrm{g})$ from a pool of corpora lutea (at dioestrus and days 15, 42 and 61 of pregnancy) was reverse transcribed into first-strand cDNA using oligo $(\mathrm{dT})$ primer and Rnase H-reverse transcriptase (Superscript II; Invitrogen Life Technologies, Carlsbad, CA, USA) in the presence of deoxynucleotides according to the manufacturer's recommendations. A 646-base pair (bp) cDNA fragment encoding a part of the extracellular domain of the LH/CG-receptor was first generated using primer pair P1 and P2 based on CDNA sequences similar among the bovine (Lussier et al. 1996), porcine (Loosfelt et al. 1989), human (Minegishi et al. 1990) and murine (McFarland et al. 1989) LH/CG-Rs (Table 1). First-strand CDNA was subjected to 30 cycles of PCR amplification using Advantage 2 polymerase mix (BD Biosciences, Palo Alto, CA, USA) and primer pair P1 and P2. Reaction times were $1 \mathrm{~min}$ denaturation at $95^{\circ} \mathrm{C}$ for the first cycle and $15 \mathrm{~s}$ per cycle thereafter, $40 \mathrm{~s}$ annealing at $60^{\circ} \mathrm{C}$ and $1 \mathrm{~min}$ extension at $72^{\circ} \mathrm{C}$ for the first 29 cycles, and 10 min extension on the final cycle at $72{ }^{\circ} \mathrm{C}$. The amplified PCR product was resolved on a $1.5 \%$ agarose gel, isolated, purified and subcloned into the TA cloning vector pCR II-TOPO (Invitrogen Life Technologies) for nucleic acid sequence determination (Genome Express, Meylan, France).

The $3^{\prime}$-end of the eLH/CG-R cDNA was subsequently isolated using sense primer $\mathrm{P} 3$ designed from the 646-bp PCR product described above (Table 1) and a degenerate antisense primer (P4) based on cDNA sequences in bovine, porcine and human LH/CG-R (Table 1) or an 
Table 1 Nucleic acid sequences of primers used for the isolation of the equine LH/CG-R CDNA and for RT-PCR. Location of nucleotides, when specified, corresponds to the eLH/CG- $R_{A} C D N A$ sequence on Fig. 1. Primer P4 is a degenerate primer where $B=T, G, C ; Y=C, T ; K=T, G$; $\mathrm{R}=\mathrm{A}, \mathrm{G}$.

\begin{tabular}{|c|c|c|}
\hline Primer name & Location & Sequence \\
\hline Forward primer $\mathrm{P} 1$ & $146-167$ & 5'-CTTTCAGAGGACTTAATGAGGT-3' \\
\hline Reverse primer P2 & $772-792$ & 5'-TCTAAAAGCACAGCAGTGGCT-3' \\
\hline Forward primer $\mathrm{P} 3$ & $570-594$ & 5'-GCTGGAGAAGATGCACAACGGAGCC-3' \\
\hline Reverse primer P4 & $2019-2047$ & 5'-CAGTTAACABTCYKTRTAGCRAGTCTTG-3' \\
\hline Reverse primer P5 & $536-560$ & 5'-TCСТTTAGСТССАGGGAAATCAGTG-3' \\
\hline Reverse primer P6 & $516-535$ & 5'-TCGTCCCGTTGAATGCATGA-3' \\
\hline Reverse primer P7 & $444-468$ & 5'-TTCGTTATTCATCССТTGAAAAGCA-3' \\
\hline Forward primer P8 & $689-710$ & 5'-TTGCCACATCATCСТАТТСТСТ-3' \\
\hline Reverse primer P9 & 1984-2005 & 5'-TATATTGGCAGTGCAATGTGGT-3' \\
\hline Reverse primer $\mathrm{P} 10$ & & 5'-СТССААТТССССТТСАТGАТАA-3' \\
\hline Forward $\beta$ actin & & 5'-CGTGACATTAAGGAGAAGCTGTGC-3' \\
\hline Reverse $\beta$ actin & & 5'-CTCAGGAGGAGCAATGATCTTGAT-3' \\
\hline
\end{tabular}

oligo(dT) as antisense primer. First-strand cDNA was amplified for 30 cycles using Advantage 2 polymerase mix (BD Biosciences) and primer pair P3 and P4 or primer pair P3 and oligo(dT) as described above.

As degenerate sense $5^{\prime}$ primers based on cDNA sequences in bovine, porcine and human LH/CG-Rs did not anneal to first strand equine LH/CG-R cDNA, we eventually used the rapid amplification of CDNA ends (RACE) technique to isolate the eLH/CG-R CDNA in the 5' direction. This was accomplished essentially as described by the manufacturer (Invitrogen Life Technologies). The gene-specific primers P5, P6 and P7 were designed from the 646-bp PCR product described above and were used in this procedure (Table 1). Briefly, first-strand cDNA was synthesized from luteal total RNA using the primer P5 and the Rnase H-reverse transcriptase Superscript II at $50{ }^{\circ} \mathrm{C}$, and then purified. An oligo-dC tail was added in the $3^{\prime}$ end of the cDNA using terminal deoxynucleotidyl transferase and dCTP. The dC-tailed cDNA was then amplified for 30 cycles using primer P6 and the Abridged Anchor Primer under the following conditions: $3 \mathrm{~min}$ at $95^{\circ} \mathrm{C}$ for one cycle, $30 \mathrm{~s}$ at $95^{\circ} \mathrm{C}, 40 \mathrm{~s}$ at $55^{\circ} \mathrm{C}$ and $1 \mathrm{~min}$ at $72^{\circ} \mathrm{C}$ for 30 cycles, $10 \mathrm{~min}$ at $72^{\circ} \mathrm{C}$ for one cycle. A second amplification was performed with the primer P7 and Abridged Universal Amplification Primer as internal primers using onetenth of the first reaction volume as template and under amplification conditions described above.

All amplified PCR products were subcloned into the TA cloning vector pCR II-TOPO (Invitrogen Life Technologies) and sequenced on both strands (Genome Express). Sequence analyses were done on the Infobiogen web site (http://www.infobiogen.fr).

\section{RT-PCR}

Single-strand cDNA was synthesized from $5 \mu \mathrm{g}$ total cellular RNA using Rnase H-reverse transcriptase (Superscript II; Invitrogen Life Technologies) and $250 \mathrm{ng}$ oligo(dT) primer as recommended by the manufacturer. PCR amplifications were performed on a geneAmp PCR System 9700 (Perkin-Elmer, Norwalk, CT, USA) and reaction mixtures contained 10 pmol of each primer, $0.4 \mathrm{mmol}$ dNTPs $~^{-1}, 1 \times$ PCR buffer, Advantage 2 polymerase mix (BD Biosciences) and cDNA template. A primer pair encoding the housekeeping gene $\beta$-actin was used as positive control (Table 1). PCR amplifications with RNAs without reverse transcription (RT) as templates were performed in parallel as negative controls. The amplification profile consisted of $5 \mathrm{~min}$ at $94^{\circ} \mathrm{C}$ followed by $25-35$ cycles of $1 \mathrm{~min}$ at $94^{\circ} \mathrm{C}, 1 \mathrm{~min}$ at $61^{\circ} \mathrm{C}$ and $1 \mathrm{~min}$ at $72^{\circ} \mathrm{C}$. The final cycle included a further $10 \mathrm{~min}$ at $72^{\circ} \mathrm{C}$ to complete extension. The amplified products were separated by electrophoresis on a $2 \%$ agarose gel stained with ethidium bromide and visualized on a UV transilluminator. Bands were individually dissected and DNA was extracted using a DNA purification kit (Wizard PCR Preps, Promega, Madison, WI, USA), subcloned into the TA cloning vector pCR II-TOPO (Invitrogen Life Technologies) and sequenced (Genome Express).

\section{Northern blot analysis}

A cDNA probe covering the extracellular domain of the eLH/CG-R (EC-probe) was generated by RT-PCR with primers EC1 and EC2 (see arrows in Fig. 1) as previously described (Saint-Dizier et al. 2003) and used for Northern blot analysis. Total cellular RNA $(15-20 \mu \mathrm{g})$ was separated by agarose gel electrophoresis in the presence of $17 \%$ formaldehyde, transferred overnight by capillary blot to a nylon membrane (Nytran Super Charge, Schleicher and Schuell, Dassel, Germany) then fixed by UV cross-linking. Blots were prehybridized for $2 \mathrm{~h}$ at $42^{\circ} \mathrm{C}$ in a buffer containing $50 \%$ formamide, $5 \times$ Denhardt's solution, $1 \%$ SDS, $5 \times$ sodium saline citrate (SSC), and $16 \mu \mathrm{l} / \mathrm{ml}$ denatured salmon sperm DNA (Invitrogen). Blots were then hybridized with the $\alpha-{ }^{32} \mathrm{P}-\mathrm{eLH} / \mathrm{CG}-\mathrm{R}$ CDNA probe overnight at $42{ }^{\circ} \mathrm{C}$ in a buffer containing $50 \%$ formamide, $2.5 \times$ Denhardt's solution, $1 \%$ SDS, $5 \times$ SSC, $10 \times$ dextran sulfate, and $16 \mu \mathrm{l} / \mathrm{ml}$ denatured salmon sperm DNA. Blots were next washed in $1 \times$ SSC plus $0.5 \%$ SDS at room temperature for $20 \mathrm{~min}$, followed by three 20 -min washes in $0.2 \times \mathrm{SSC}$ plus $0.5 \%$ SDS at $68^{\circ} \mathrm{C}$. Membranes 


\section{$\mathrm{eLH} / \mathrm{CG}-\mathrm{R}_{\mathrm{A}}$ :}

CTG CTG CCG CAA GCG CTG CGC GGG GCG CCC TGC CCC GAG CCC TGC CGC TGC CCG CCC GAC GGC GCC CTG AGC TGC CCC TAT ACA GAG TGT TAA CTGT

Y T $\mathrm{T}$ C *

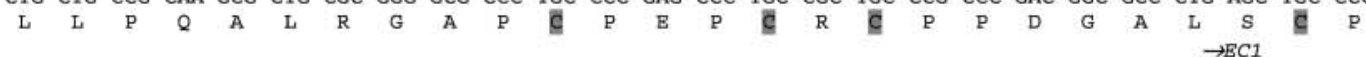
GGC CCG CGG AGG AAC CTC TCC CGA CTA TCA CTC ACC TAT CTT CCT ATC AAA GTA ATC CCA TCT CAA GCT TTC AGA GGA $\begin{array}{lllllllllllllllllllllllllll}G & P & R & R & \underline{N} & L & S & R & L & S & L & T & Y & L & P & I & K & V & I & P & S & Q & A & F & R & G\end{array}$ CTT GAT GAA GTT GTA AAA ATT GAA ATC TCT CAG AGT GAT TCC CTG GAA AAG ATA GAA GCT AAT GCC TTT GAC AAC CTC CTC AAT TTG TCT GAA ATA CTG ATC CAG AAC ACC AAA AAC CTA GTG TAC ATC GAG CCT GGA GCA TTT ACA AAT CTC CCC $\begin{array}{lllllllllllllllllllllllllllll}L & N & L & S & E & I & L & I & Q & \mathbb{N} & T & K & \mathbb{N} & L & V & Y & I & E & P & G & A & F & T & N & L & P\end{array}$ CGG TTA AAA TAC CTA AGC ATC TGT AAC ACA GGC ATC CGA AAG CTT CCA GAT GTT ACC AAG ATC TTC TCC TCT GAA ATT

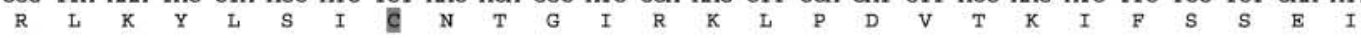
AAT TTC ATT CTG GAA ATT TGC GAT AAC TTA CAC ATA ACC ACC ATA CCA GGA AAT GCT TTT CAA GGG ATG AAT AAC GAA \begin{tabular}{lllllllllllllllllllllllllllllllll}
$N$ & $F$ & $I$ & $L$ & $E$ & $I$ & $\mathbb{C}$ & $D$ & $N$ & $L$ & $H$ & $I$ & $T$ & $T$ & $I$ & $P$ & $G$ & $N$ & $A$ & $F$ & $Q$ & $G$ & $M$ & $N$ & $N$ & $E$ \\
\hline
\end{tabular} TCC ATA ACA CTC AAA CTA TAT GGA AAT GGA CTT GAA GAA ATA CAA AGT CAT GCA TTC AAC GGG ACG ACA CTG ATT TCC $\begin{array}{lllllllllllllllllllllllllllll}S & I & T & \text { L } & K & \text { L } & Y & G & N & G & \text { L } & \text { E } & \text { E } & \text { I } & Q & S & H & A & F & \underline{N} & G & T & T & I & I & S\end{array}$ CTG GAG CTA AAG GAA AAT GCC CAG CTG GAG AAG ATG CAC AAC GGA GCC TTC CAG GGG GCC ACA GGG CCC AGC ATC TTG

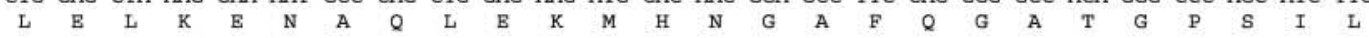
GAT ATT TCT TCC ACC AAA CTG CAG GCC CTA CCT AGC TAT GGG CTG GAG TCC ATT CAG ACG CTA ATT GCC ACA TCA TCC $\begin{array}{llllllllllllllllllllllllllllll} & D & I & S & S & T & K & L & Q & A & L & P & S & Y & G & L & E & S & I & Q & T & \text { L } & I & A & T & S & S\end{array}$ TAT TCT CTA AAA AAA TTA CCG TCA AGA GAA AAA TTT ACC AAT CTC CTG GCT GCC ACA CTG ACT TAC CCA AGC CAC TGC

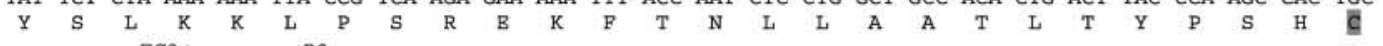
$E C 2 \leftarrow$
TGT GCT TTT AGA AAC TTG CCA ACA AAA GAA CAG AAT TTT TCA TTT TCC ATT TTT GAA AAC TTT TCC CAA CAA TGT GAA

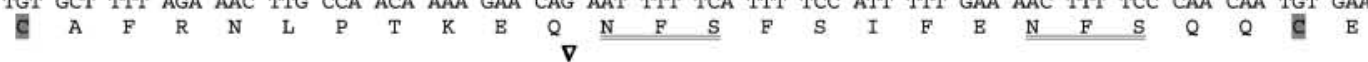
AGC ACA GCA AGG AAA CCA AAT AAT GGA ACA CTT TAT TCT GCC AGC TTT GCT GAG AGT GAA CTG AGT GGC TGG GAT TAT

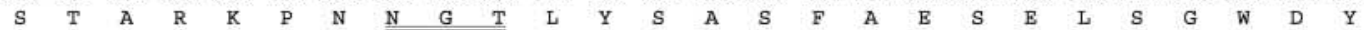
GAC GAT GGT TTC TGC CCA CAC AAG ACA CTC CGA TGT GCT CCT GAA CCA GAT GCT TTT AAT CCC TGT GAA GAT ATT ATG

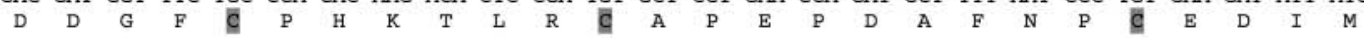
GGC TAT GAC TTC CTT AGg GTC CTG ATT TGG CTG ATT AAT ATC CTA GCC ATC ATG GGA Aat GTG ACT GTC CTC TTT GTT \begin{tabular}{lllllllllllllllllllllllllllll}
$G$ & $Y$ & $D$ & $F$ & $L$ & $R$ & $V$ & L & I & W & L & I & N & I & L & A & I & $M$ & $G$ & N & V & T & V & L & F & V \\
\hline
\end{tabular} CTC CTG ACC AGT CAT TAC AAA CTA ACA GTG CCC CGT TTT CTC ATG TGC AAT CTC TCT TTT GCA GAC TTT TGC ATG GGG \begin{tabular}{llllllllllllllllllllllllllllllll}
$L$ & $L$ & $T$ & $S$ & $H$ & $Y$ & $K$ & $L$ & $T$ & $V$ & $P$ & $R$ & $F$ & $L$ & $M$ & $C$ & $N$ & $L$ & $S$ & $F$ & $A$ & $D$ & $F$ & C & $M$ & $G$ \\
\hline
\end{tabular} CTC TAT CTG CTG CTC ATT GCC TCA GTT GAT TCC CAA ACC AAA GGC CAg TAT TAT AAC CAT GCC ATA GAT TGG CAg ACA $\begin{array}{lllllllllllllllllllllllllllll}\mathrm{L} & \mathrm{Y} & \mathrm{L} & \mathrm{L} & \mathrm{L} & \mathrm{I} & \mathrm{A} & \mathrm{S} & \mathrm{V} & \mathrm{D} & \mathrm{S} & \mathrm{Q} & \mathrm{T} & \mathrm{K} & \mathrm{G} & \mathrm{Q} & \mathrm{Y} & \mathrm{Y} & \mathrm{N} & \mathrm{H} & \mathrm{A} & \mathrm{I} & \mathrm{D} & \mathrm{W} & Q & \mathrm{~T}\end{array}$ GGG AGT GGG TGT AGT GCT GCT GGC TTT TTC ACT GTA TTT GCA AGT GAA CTT TCT GTC TAC ACC CTC ACA GTC ATC ACA

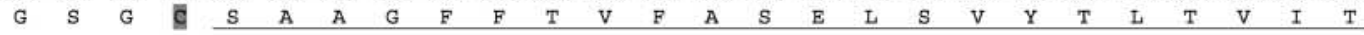
CTA GAA AGA TGG CAC ACC ATC ACC TAT GCT ATT CAG CTG GAC CAA AAA CTA CGA TTA AGA CAT GCC ATT CCA ATT ATG \begin{tabular}{lllllllllllllllllllllllllllll}
$\mathrm{L}$ & $\mathrm{E}$ & $\mathrm{R}$ & $\mathrm{W}$ & $\mathrm{H}$ & $\mathrm{T}$ & $\mathrm{I}$ & $\mathrm{T}$ & $\mathrm{Y}$ & $\mathrm{A}$ & $\mathrm{I}$ & $\mathrm{Q}$ & $\mathrm{L}$ & $\mathrm{D}$ & $\mathrm{Q}$ & $\mathrm{K}$ & $\mathrm{L}$ & $\mathrm{R}$ & $\mathrm{L}$ & $\mathrm{R}$ & $\mathrm{H}$ & $\mathrm{A}$ & $\mathrm{I}$ & $\mathrm{P}$ & $\mathrm{I}$ & $\mathrm{M}$ \\
\hline
\end{tabular} CTT GGA GGA TGG CTC TTT TCT ACT CTA ATT GCT ATG TTG CCC CTT GTG GGT GTC AGC AAT TAC AGG AAG GTC AGC ATT $\begin{array}{llllllllllllllllllllllllllll}\text { L } & G & G & \text { W } & \text { L } & \text { F } & S & \text { T } & \text { L } & \text { I } & \text { A } & \text { M } & \text { L } & \text { P } & \text { L } & \text { V } & G & \text { V } & S & \text { N } & \text { Y } & \text { R } & \text { K } & \text { V } & S & \text { I }\end{array}$ TGC CTC CCC ATG GAT ATA GAA ACC ACT CTC TCA CAA GTC TAC ATA TTA ACC ATC CTG ATA CTC AAT GTG GTA GCC TTC

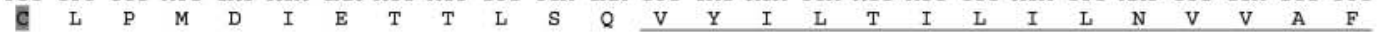
TTC ATC ATT TGT GCT TGC TAC ATT AAA ATT TAT TTT GCA GTT CAA AAT CCA CAA CTG ATA GCT ACC AAC AAA GAC ACA $\begin{array}{lllllllllllllllllllllllllll}\mathrm{F} & \mathrm{I} & \mathrm{I} & \mathrm{C} & \mathrm{A} & \mathrm{C} & \mathrm{Y} & \mathrm{I} & \mathrm{K} & \mathrm{I} & \mathrm{Y} & \mathrm{F} & \mathrm{A} & \mathrm{V} & \mathrm{Q} & \mathrm{N} & \mathrm{P} & \mathrm{Q} & \mathrm{L} & \mathrm{I} & \mathrm{A} & \mathrm{T} & \mathrm{N} & \mathrm{K} & \mathrm{D} & \mathrm{T}\end{array}$

AAG ATT GCT AAG AAA ATG GCA GTC CTC ATC TTC ACC GAT TTC ACC TGC ATG GCA CCT ATC TCT TTT TTT GCC ATT TCA \begin{tabular}{llllllllllllllllllllllllllllll}
$\mathrm{K}$ & $\mathrm{I}$ & $\mathrm{A}$ & $\mathrm{K}$ & $\mathrm{K}$ & $\mathrm{M}$ & $\mathrm{A}$ & $\mathrm{V}$ & $\mathrm{L}$ & $\mathrm{I}$ & $\mathrm{F}$ & $\mathrm{T}$ & $\mathrm{D}$ & $\mathrm{F}$ & $\mathrm{T}$ & $\mathrm{C}$ & $\mathrm{M}$ & $\mathrm{A}$ & $\mathrm{P}$ & $\mathrm{I}$ & $\mathrm{S}$ & $\mathrm{F}$ & $\mathrm{F}$ & $\mathrm{A}$ & $\mathrm{I}$ & $\mathrm{S}$ \\
\hline
\end{tabular} GCT GCC TTC AAA GTG CCC CTT ATC ACA GTA ACC AAT TCT AAA GTT TTA CTG GTT CTC TTT TAT CCT GTC AAT TCT TGT \begin{tabular}{llllllllllllllllllllllllll}
$A$ & $A$ & $F$ & $K$ & $V$ & $P$ & L & $I$ & $T$ & $V$ & $T$ & $N$ & $S$ & $K$ & $V$ & L & L & V & L & F & Y & P & V & N & S & C. \\
\hline
\end{tabular} GCC AAT CCA TTT CTG TAC GCG ATT TTC ACA AAG GCA TTC CGA AGA GAT TTC TTT CTG TTG CTG AGC AAA TTT GGC TGC

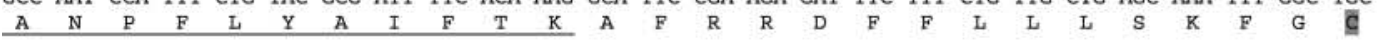
TGT AAA CAT CGG GCT GAA CTT TAT AGA AGg AAg GAT TTT TCA GCT TAT ACC TCC AAG TGG AAg AAT GGC tTC ACT GGA \begin{tabular}{llllllllllllllllllllllllllll}
\hline E & $\mathrm{K}$ & $\mathrm{H}$ & $\mathrm{R}$ & $\mathrm{A}$ & $\mathrm{E}$ & $\mathrm{L}$ & $\mathrm{Y}$ & $\mathrm{R}$ & $\mathrm{R}$ & $\mathrm{K}$ & $\mathrm{D}$ & $\mathrm{F}$ & $\mathrm{S}$ & $\mathrm{A}$ & $\mathrm{Y}$ & $\mathrm{T}$ & $\mathrm{S}$ & $\mathrm{K}$ & $\mathrm{W}$ & $\mathrm{K}$ & $\mathrm{N}$ & $\mathrm{G}$ & $\mathrm{F}$ & $\mathrm{T}$ & $\mathrm{G}$
\end{tabular} CDA $P 9 \leftarrow$

TCA AAT Aag TCT TCC CAg CCC ACC TTG Aag CTG ACC ACA TTG CAC TGC CAA TAT ACA GCT GTC CCA GAC Aag ACT TGC 2028

eLH/CG-R $R_{B}$ : ACA CTG CAT TCC GAA GAG ATT TCT TTC TGT TGC TGA

78 52 234 78 312 104 390 130 468 156 546 182 624 208 702 234 780 260 858 286 936 312 1014 338 1092
364 1170 $\begin{array}{r}390 \\ \hline\end{array}$ 1248 416 1326 442 1404 468 1482 494 1560 520 1638 546 1716 572 1794 598 1872 624 1950 650 676 2047 680

eLH/CG-R e $_{C} \quad$ ACA CTG GAG ACA GCA AGA TAC CAG ATG AAT GGC CTG GTC ACA TGA $10 \leftarrow$ $\begin{array}{lllllllllllllll}T & L & E & T & A & R & Y & Q & M & N & G & L & V & T & *\end{array}$ 
were exposed to a Phosphorlmager screen (Molecular Dynamics, Sunnyvale, CA, USA) at room temperature for 16-18 h before quantification. Membranes were then washed three times for 20 min with a boiling solution of $2 \times$ SSC plus $0.2 \%$ SDS to remove the probe and rehybridized with the human RNA $18 \mathrm{~S}$ probe from Ambion, Inc. (Austin, TX, USA). Membranes hybridized with the 18S probe were exposed for $1 \mathrm{~h}$ to a Phosphorlmager screen. All hybridization signals were quantified using ImageQuant software (Molecular Dynamics). Each RNA sample was analyzed 2 to 5 times on different blots. The RNA sample of one CL at the diestrous stage (day 8 post-ovulation) was used as internal control in each blot. The intensities for LH/CG-R signals were adjusted with $18 \mathrm{~S}$ signal values in each blot and the LH/CG-R:18S ratio values were normalized between blots according to the LH/CG-R:18S ratio value of the internal control.

\section{Statistical analysis}

The concentrations of mRNA levels are shown as means \pm S.E.M. Three stages of pregnancy were considered according to the known pattern of eCG secretion: before the onset of eCG secretion (days 14-31 for $\mathrm{CL}$ ), during eCG secretion (days 42-89 for CL and days 44-101 for fetal gonads) and after eCG secretion (day 151 for $C L$ and days 151-222 for fetal gonads). The relative levels of mRNAs were compared between stages of pregnancy, irrespective of other variables, with the nonparametric Kruskall-Wallis test in the primary $C L$ and with the nonparametric Wilcoxon-Mann-Whitney in the fetal gonads. Tests were all performed using StatXact 5 (CYTEL, Cambridge, MA, USA; http://www.cytel.com/). Differences were considered to be significant when $P<0.05$.

\section{Results}

\section{Nucleotide sequence analysis of eLH/CG-R CDNA isoforms}

Based on the conserved sequences of the human, porcine, bovine and murine LH/CG-R CDNAs, the primer pair P1 and P2 was designed and used in RT-PCR reaction using total RNA from a pool of corpora lutea as template. A 646-bp PCR product was obtained, subcloned, then sequenced and found to be homologous with known mammalian LH/CG-R cDNAs. The sequence information from the 646-bp fragment combined with RT-PCR and
5'-RACE products generated a 2047-bp eLH/CG-R cDNA (eLH/CG-RA: Fig. 1), spanning over a part of the signal peptide plus the entire extracellular, transmembrane and intracellular domains of the eLH/CG-R. The cDNA sequence (excluding primer sequence) of eLH/CG- $\mathrm{R}_{\mathrm{A}}$ (accession number AY464091 to GenBank) showed 92.3, 91.6, 88 and $85.7 \%$ homologies with reported cDNA sequences of porcine (Loosfelt et al. 1989), bovine (Lussier et al. 1996), human (Minegishi et al. 1990) and rat (McFarland et al. 1989) LH/CG-R respectively, and showed $64.6 \%$ homology with the equine follicle-stimulating hormone (FSH) receptor (FSH-R) cDNA sequence (Robert et al. 1994). The deduced 680-amino acids sequence of eLH/CG- $R_{A}$ cDNA was similarly conserved among mammals (pig 92.5\%, cow 91.6\%, human $89.1 \%$ and rat $87.4 \%$ ) and showed $58 \%$ homology with the equine FSH-R. Alignment with the porcine sequence suggests a putative cleavage site of the signal peptide between Gly $^{8}$ and $\mathrm{Ala}^{9}$ (Loosfelt et al. 1989). Thus, the $\mathrm{eLH} / \mathrm{CG}-\mathrm{R}_{\mathrm{A}}$ CDNA would encode a mature protein of 672 amino acids. The putative 335-amino acid extracellular domain of eLH/CG-R contains 12 cysteine residues conserved in all species and seven potential $\mathrm{N}$-linked glycosylation sites $(\mathrm{N}-\mathrm{X}-\mathrm{S} / \mathrm{T})$, i.e. one more than in the human, porcine, bovine and rat LH/CG-R sequences (Fig. 1). The transmembrane domain is composed of 266 amino acid residues including seven hydrophobic segments potentially spanning the cytoplasmic membrane and 8 conserved cysteine residues. The 71-amino acid $\mathrm{COOH}$ terminal intracellular domain contains three conserved cysteine residues. The putative intracellular loops as well as the intracellular domain display several serine, threonine and tyrosine residues that are potential sites for phosphorylation.

Two other types of clones were isolated by RT-PCR. Using primer pair P3 and P4, seven of the eleven sequenced clones coded for a splice variant of the eLH/CG-R $R_{A}$ CDNA and was named eLH/CG- $R_{B}$. The eLH/CG-R $R_{B} C D N A$ spliced out of frame from the $3^{\prime}$-end of exon $X$ (at bp 891) into the coding region of exon XI (at bp 1829), thus encoding a putative protein of 306 amino acids without transmembrane and intracellular domains (Fig. 1). Using primer pair P3 and an oligo(dT), all three sequenced clones encoded a third eLH/CG-R splice variant, named eLH/CG- $R_{C}$. This variant spliced from the $3^{\prime}$ end of exon $X$ (at bp 891) into a divergent nucleotide sequence, which was not found in the eLH/CG-R $R_{A}$ CDNA,

Figure 1 Nucleic acid and deduced amino acid sequences of intact (eLH/CG-RA) and truncated (eLH/CG-R and eLH/CG-R $R_{C}$ equine LH/CG-R CDNA. The putative cleavage site of the peptide signal after alignment with the porcine LH/CG-R is indicated by an arrow ( $\Downarrow$ ). Conserved cysteine residues are highlighted by gray boxes. The equine-specific $\mathrm{N}$-glycosylation site is indicated in bold letters double underlined, and other double underlines indicate the six $\mathrm{N}$-linked glycosylation sites conserved among other mammalian LH/CG-Rs. Single underlines indicate the seven predicted transmembrane-spanning domains. The point of divergence between intact and truncated eLH/CG-R CDNA isoforms is indicated by an arrowhead $(\nabla)$ and the point of junction for eLH/CG- $R_{B}$ is indicated by an arrow $(\downarrow)$. The sites of the primers P8, P9 and P10, used in RT-PCR, are indicated on the CDNA sequence. The primer pair EC1 and EC2, also indicated, was used to generate the eLH/CG-R cDNA ECprobe for Northern blot analysis. (Accession number AY464091 to GenBank.) 
and contained an in-frame TGA stop codon (eLH/CG- $\mathrm{R}_{\mathrm{C}}$; Fig. 1). This divergent sequence is 590-bp long and contains a poly-A tail at its $3^{\prime}$-end. The eLH/CG-R CDNA isoform encoded a putative protein of 310 amino acids without transmembrane and intracellular domains.

\section{Expression of eLH/CG-R mRNA isoforms detected by RT-PCR}

The expression of intact (eLH/CG- $\left.\mathrm{R}_{\mathrm{A}}\right)$ and truncated $\left(\mathrm{eLH} / \mathrm{CG}-\mathrm{R}_{\mathrm{B}}\right.$ and eLH/CG-R ) eLH/CG-R mRNA isoforms was examined in the primary $C L$ and in fetal gonads at different stages of early and mid- pregnancy using qualitative RT-PCR. A primer pair encompassing exon IX through the end of exon XI (primers P8 and P9; see Table 1 and Fig. 1) revealed the expression of both eLH/CG- $R_{A}$ (1318-bp band) and eLH/CG-R $\mathrm{B}_{\mathrm{B}}$ (380-bp band) mRNAs in the primary $\mathrm{CL}$ from day 14 to day 83 of pregnancy whereas only the eLH/CG- $R_{B}$ form was detected at day 89 and faintly detected at day 151 (Fig. 2a). A non-specific 500-bp product was also weakly amplified with primer pair P8 and P9 in some samples. The sense primer P8 combined with an antisense primer located in the non coding region of $\mathrm{eLH} / \mathrm{CG}-\mathrm{R}_{\mathrm{C}}$ mRNA (primer $\mathrm{P} 10$; see Table 1 and Fig. 1) revealed the expression of the eLH/CG-R $\mathrm{R}_{\mathrm{C}}$ mRNA isoform (528-bp band) from day 14 to day 89 of pregnancy. However, no luteal expression of eLH/CG-R $R_{C}$ mRNA could be seen at day 151 of pregnancy (Fig. 2b).

In fetal gonads, the expression of eLH/CG- $\mathrm{R}_{\mathrm{A}}$, eLH/CG$R_{B}$ and eLH/CG- $R_{C}$ mRNAs was detected as early as day 44 of pregnancy and at the following days examined until day 222 of pregnancy (Fig. 3a and 3b). The signal for

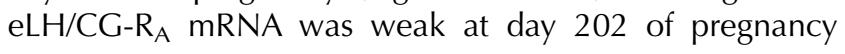

although it could not be determined whether this change was an individual variation or a genuine developmental change. The $\beta$-actin signal was detected in all samples (374-bp band; Fig. 2c and 3c) and no signal could be seen with RNAs without RT as templates.

\section{Expression of eLH/CG-R mRNA isoforms detected by Northern blot analysis}

Northern blot analysis with a cDNA probe covering the major part of the extracellular domain of the eLH/CG-R (EC-probe) revealed seven eLH/CG-R mRNA transcripts at $7,5.7,4.9,3.9,2.8,1.8 \mathrm{~kb}$ and $0.6 \mathrm{~kb}$ in the primary $\mathrm{CL}$ (Fig. 4), as shown previously (Saint-Dizier et al. 2003). The number and apparent size of mRNA transcripts did not change from day 14 to day 89 in the primary $C L$, whereas no hybridization signal was observed in the day 151 primary CL. Northern blot analysis of total RNA from fetal gonads with the EC-probe revealed two transcripts at 3.9 and $1.8 \mathrm{~kb}$ on days 44 and 62 , and six transcripts at 7 , $5.7,4.9,3.9,2.8$ and $1.8 \mathrm{~kb}$ from day 70 to day 222 of pregnancy (Fig. 5). Furthermore, whereas four major transcripts at 7, 5.7, 3.9 and $1.8 \mathrm{~kb}$ were observed in the primary $\mathrm{CL}$, only the $1.8 \mathrm{~kb}$ hybridization signal was predominant in the fetal gonads. However, it is not known if these transcripts are translated. No hybridization signal was observed with RNA samples from adult lung, kidney, spleen or liver (data not shown).

\section{Semiquantitative analysis of eLH/CG-R mRNA isoforms}

The relative value of the major $1.8 \mathrm{~kb}$ mRNA transcript expressed in fetal gonads was quantified and compared with relative values of major eLH/CG-R transcripts

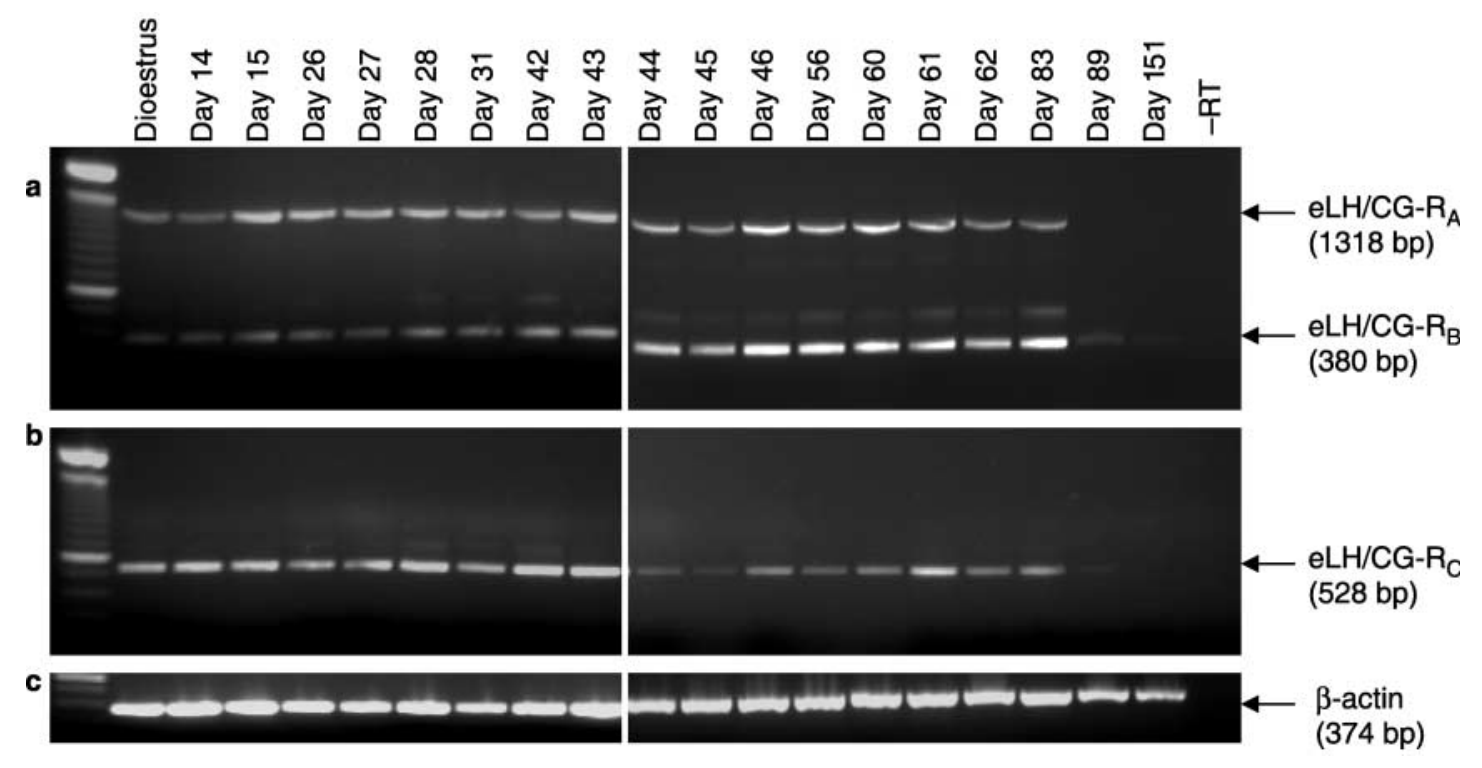

Figure 2 Representative amplification of the alternatively spliced eLH/CG- $R_{A}$, eLH/CG- $R_{B}$ (a) and eLH/CG- $R_{C}$ (b) isoforms by RT-PCR in the primary corpus luteum from one cyclic mare at day 8 post-ovulation (Dioestrus) and from mares at days $14-151$ of pregnancy. Expression of the $\beta$-actin gene was used as positive control (c). -RT corresponds to a PCR carried out without reverse transcriptase. 


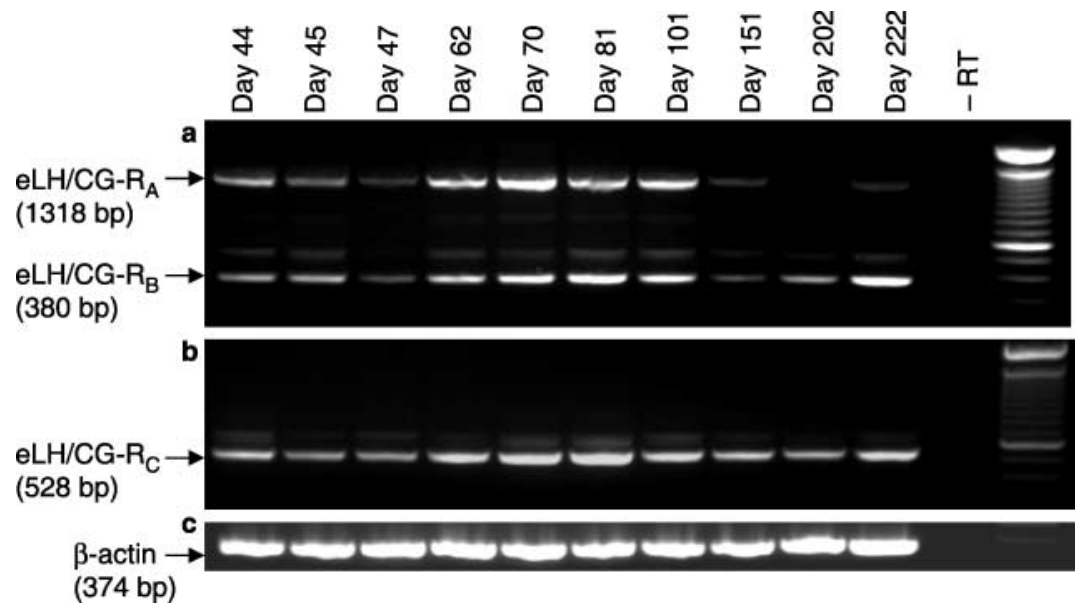

Figure 3 Representative amplification of the alternatively spliced eLH/CG- $R_{A}$, eLH/CG- $R_{B}$ (a) and eLH/CG- $R_{C}$ (b) isoforms by RT-PCR in fetal gonads at days 44-222 of pregnancy. Expression of the $\beta$-actin gene was used as positive control (c). $-\mathrm{RT}$ corresponds to a PCR carried out without reverse transcriptase.

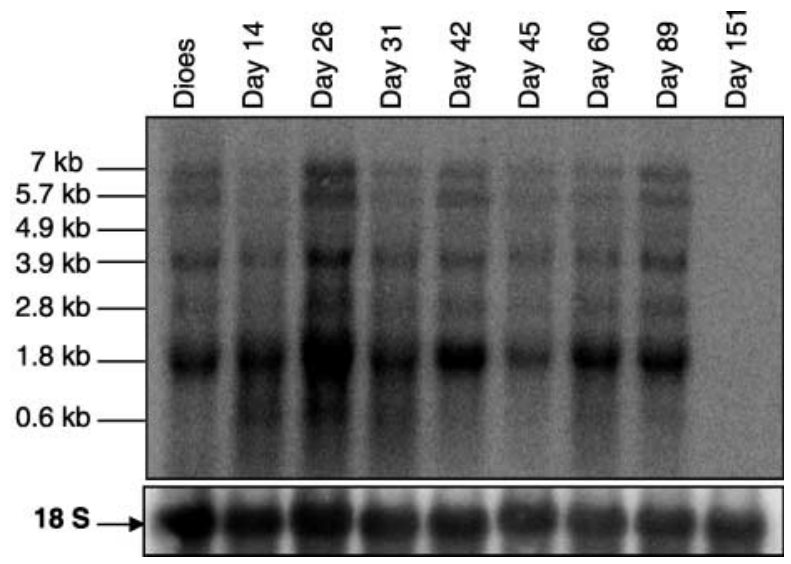

Figure 4 Representative Northern blot analysis of total RNA from one $\mathrm{CL}$ at the dioestrous stage (Dioes) as internal control and $\mathrm{CL}$ from pregnant mares before the onset of eCG secretion (days 14-31), during eCG secretion (days 42-89) and after eCG secretion (day 151) hybridized with the cDNA EC-probe (top panel) and the RNA 18Sprobe (bottom panel) for normalization.

expressed in the primary CL during pregnancy (Fig. 6). The major $1.8 \mathrm{~kb}$ mRNA transcript was 1.2 to 3 times less expressed in fetal gonads than in the primary $\mathrm{CL}$ or in the dioestrous $\mathrm{CL}$ used as internal control in each blot. The relative intensity of the $1.8 \mathrm{~kb}$ major transcript tended to increase in fetal gonads at days 70, 81 and 101 of pregnancy. However, there was no significant change in the $1.8 \mathrm{~kb} \mathrm{mRNA}$ intensity between stages of pregnancy from day 44 to day 222 in fetal gonads. In the primary $\mathrm{CL}$, the relative values of the major $7,5.7,3.9$ and $1.8 \mathrm{~kb}$ mRNA transcripts tended to decrease $(P=0.08,0.2,0.06$ and 0.14 respectively) between stages of pregnancy from day 14 to day 151 of pregnancy (Fig. 6).

\section{Discussion}

Three different eLH/CG-R cDNA isoforms (eLH/CG- $\mathrm{R}_{\mathrm{A}, \mathrm{B}, \mathrm{C}}$ ) were isolated from a pool of equine corpora lutea and identified by nucleotide sequence analysis of RT-PCR and 5'-RACE products. The full-length eLH/CG-R cDNA

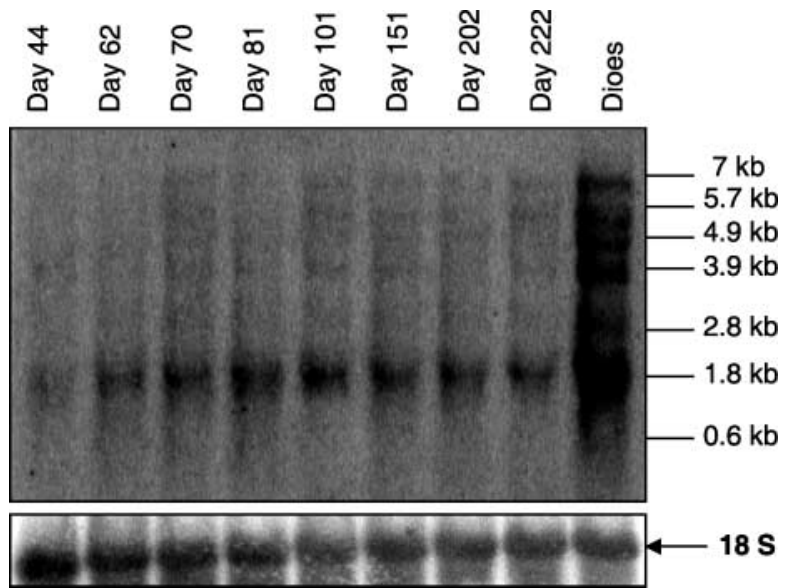

Figure 5 Representative Northern blot analysis of total RNA from equine fetal gonads during eCG secretion (day 44-101) and after eCG secretion (day 151-222), and from one CL at the dioestrous stage (Dioes) as internal control, hybridized with the cDNA EC-probe (top panel) and the RNA 18S-probe (bottom panel) for normalization.

$\left(\mathrm{eLH} / \mathrm{CG}-\mathrm{R}_{\mathrm{A}}\right)$ as well as truncated forms encoding receptors without transmembrane and intracellular domains $\left(\mathrm{eLH} / \mathrm{CG}-\mathrm{R}_{\mathrm{B}, \mathrm{C}}\right)$ were expressed from day 14 to day 83 in the primary $\mathrm{CL}$ and from day 44 to day 222 of pregnancy in fetal gonads. In contrast, the primary $\mathrm{CL}$ at days 89 and 151 expressed only truncated forms of the eLH/CG-R cDNA. The relative values of major mRNA transcripts tended to decrease in the primary $\mathrm{CL}$ whereas the unique major $1.8 \mathrm{~kb}$ mRNA in fetal gonads was steadily expressed during pregnancy. These results show that the expression of eLH/CG-R mRNAs occurs in fetal gonads before it ends in the primary $\mathrm{CL}$ and thus parallels the gradual change from a luteal to a feto-placental steroidogenesis during equine pregnancy.

This study reports the first cloning and sequencing of the full-length equine LH/CG-R cDNA. The deduced 680amino acids sequence showed high homology with reported LH/CG-R sequences in other mammals, especially with the porcine $(92.3 \%$ homology) and the bovine (91.6\%) LH/CG-R proteins. In contrast to all other 

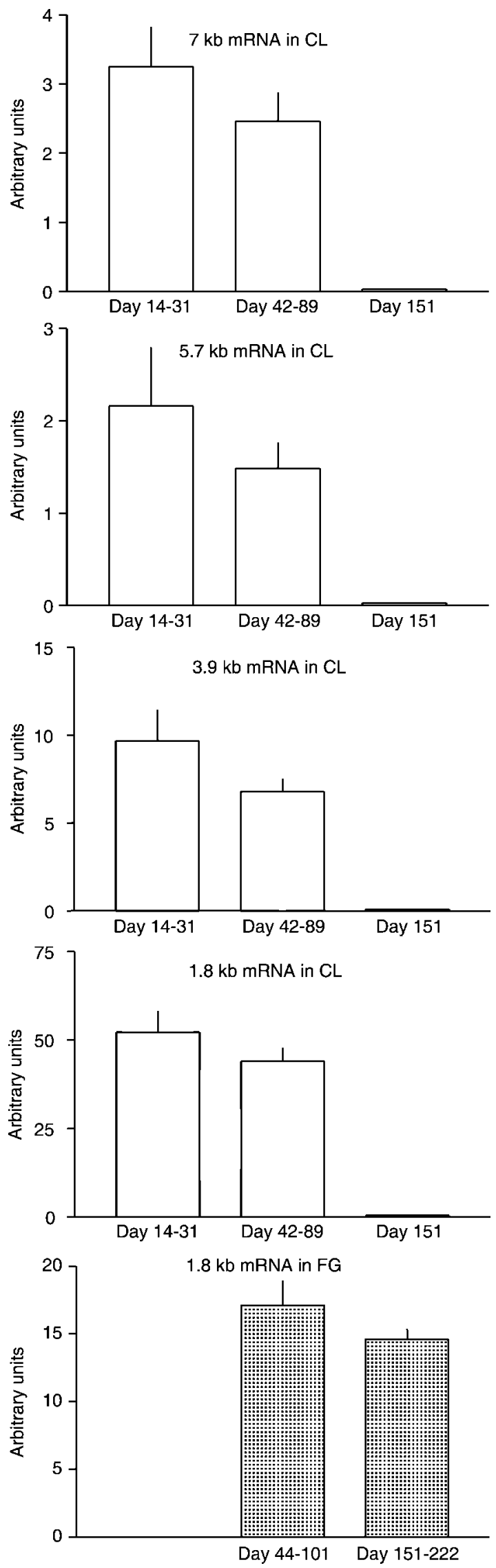

known mammalian LH/CG-Rs, which contain six conserved consensus sequences for $\mathrm{N}$-linked carbohydrates, the eLH/CG-R displays a seventh putative $\mathrm{N}$-glycosylation site in the $\mathrm{N}$-terminal region of the extracellular domain, created by a Gly31Asn replacement (Gly23Asn replacement in the mature protein) (Loosfelt et al. 1989, McFarland et al. 1989, Minegishi et al. 1990, Lussier et al. 1996). Interestingly, while most mammalian FSH-Rs contain three highly conserved potential sites for $\mathrm{N}$-glycosylation, the equine FSH-R also displays an additional $\mathrm{N}$-glycosylation site in its extracellular domain (Robert et al. 1994). It has been hypothesized that this fourth $\mathrm{N}$-glycosylation site could be involved in preventing eLH/CG binding to the eFSH-R (Richard et al. 1997). Although it is known that five of the six N-glycosylation sites in the porcine LH/CG-R (Vu-Hai et al. 2000) and all six sites in the rat LH/CG-R (Davis et al. 1997) are indeed glycosylated, the potential roles of these glycosidic chains remain unclear. Indeed, the nonglycosylated rat LH/CG-R can be properly folded and expressed at the cell surface, and can bind hormone and transduce signals (Davis et al. 1997). It would be of interest to determine whether all seven $\mathrm{N}$-glycosylation sites of the eLH/CG-R contain carbohydrates. Furthermore, eCG binds to the eLH/CG-R with only one tenth or less the affinity of pituitary eLH in equine tissues (Stewart \& Allen 1979, 1981, Guillou \& Combarnous 1983). The possible implication of the equine LH/CG-R extra N-glycosylation site in this differential binding affinity should also be examined.

Northern blot analysis using a cDNA probe encoding the extracellular domain of the eLH/CG-R revealed seven mRNA transcripts at 7, 5.7, 4.9, 3.9, 2.8, 1.8 and $0.6 \mathrm{~kb}$ in the primary CL. In a previous study, the presence of multiple eLH/CG-R transcripts seemed to arise in part from alternate splicing of the eLH/CG-R primary transcript since a probe covering the transmembrane domain of the receptor hybridized to only four of these seven transcripts (at 7, 4.9, 3.9 and $1.8 \mathrm{~kb}$ ) (Saint-Dizier et al. 2003). The present work shows that the alternate splicing of the LH/CG-R primary transcript indeed occurs in the primary $\mathrm{CL}$ and in fetal gonads and gives rise to at least two splicing variants (eLH/CG- $R_{B}$ and $\left.e L H / C G-R_{C}\right)$ in addition to the full-length eLH/CG-R mRNA (eLH/CG-RA). The point of divergence between the full-length eLH/CG-R cDNA and the two truncated cDNA isoforms is the same as the one described for the porcine LH/CG-R cDNA and corresponds to the $3^{\prime}$ end of exon X (Loosfelt et al. 1989). One of the three splicing variants described for the porcine LH/CG-R (the D form) has been shown to splice in frame at the transmembrane to intracellular sequence junction and thus contained a putative intracellular domain.

Figure 6 Relative intensities of eLH/CG-R major mRNA transcripts in the primary $\mathrm{CL}$ and in fetal gonads (FG) before eCG secretion $(\mathrm{CL}$ : days $14-31, n=6)$, during eCG secretion (CL: days $42-89, n=11$; FG: days $44-101, n=7)$ and after eCG secretion (CL: day 151, $n=1$; FG: days $151-222, n=3$ ). Values are means \pm S.E.M. 
In contrast, the eLH/CG- $R_{B}$ form displayed a frameshift at approximately the same point of junction as the porcine $\mathrm{D}$ variant and was thus truncated for the putative transmembrane and intracellular domains. The eLH/CG- $\mathrm{R}_{\mathrm{C}}$ variant, which completely lacks the exon XI encoding the transmembrane and intracellular domains, was similar to the truncated form found in the turkey ovary (You et al. 2000). Nevertheless, such a variant had not previously been described in mammalian species. The three eLH/CG-R transcripts that have been shown to lack the transmembrane domain by Northern blot analysis were at 5.7, 2.8 and $0.6 \mathrm{~kb}$ (Saint-Dizier et al. 2003). The $\mathrm{eLH} / \mathrm{CG}-\mathrm{R}_{\mathrm{B}}$ and $\mathrm{eLH} / \mathrm{CG}-\mathrm{R}_{\mathrm{C}} \mathrm{CDNA}$ isoforms could correspond to the $5.7 \mathrm{~kb}$ and/or to the $2.8 \mathrm{~kb}$ transcripts observed on Northern blots. Nevertheless, as the open reading frame of the full eLH/CG-R is approximately $2.1 \mathrm{~kb}$, other processes like alternate transcriptional start sites and/or multiple sites and lengths of polyadenylation are probably involved in large differences in LH/CG-R mRNAs sizes.

The detection of eLH/CG-R mRNA isoforms by RT-PCR showed that the expression of the eLH/CG- $R_{A}$ isoform ceased in the primary $\mathrm{CL}$ between days 83 and 89 of pregnancy. At days 89 and 151 of pregnancy, only truncated forms of eLH/CG-R mRNAs without transmembrane sequence $\left(\mathrm{eLH} / \mathrm{CG}-\mathrm{R}_{\mathrm{B}}\right.$ and $\left.\mathrm{eLH} / \mathrm{CG}-\mathrm{R}_{\mathrm{C}}\right)$ were detected by RT-PCR. This change in eLH/CG-R mRNA alternative splicing occurs while the feto-placental steroidogenesis is sufficient to support pregnancy (Holtan et al. 1979). However, the primary $\mathrm{CL}$ is maintained and continues to secrete progesterone and estrogens until days 160-180 of pregnancy, probably stimulated by eCG (Squires et al. 1974, Ginther 1992a). In a previous study, ${ }^{125}$ I-eLH saturation binding assays performed on luteal membranes showed that the primary CL at days 83-101 of pregnancy bound ${ }^{125} \mathrm{I}$-eLH with high affinity and displayed a substantial level of membrane eLH/CG binding sites, which was $24.7 \%$ of the level measured at days $14-31$ of pregnancy (Saint-Dizier et al. 2003). Furthermore, luteal membranes at day 151 also bound ${ }^{125} \mathrm{I}$-eLH (data not shown). It is assumed that luteal cells of the primary $\mathrm{CL}$ still have membrane eLH/CG-Rs despite only truncated eLH/CG-R mRNAs being synthesized between days 89 and 151 of pregnancy. It is thus supposed that luteal eLH/CG-Rs exhibit long half-lives over this period of time.

As shown by RT-PCR, the eLH/CG- $R_{A}$ isoform was expressed in fetal gonads as early as day 44 of pregnancy and in all gonads until day 222 of pregnancy, which was the last time point examined. However, the $1.8 \mathrm{~kb}$ transcript was largely predominant in Northern blots performed on the same samples, whereas three additional mRNA transcripts with larger sizes (7, 5.7 and $3.9 \mathrm{~kb})$ were predominantly expressed in the adult primary CL. Since the size of the $1.8 \mathrm{~kb}$ transcript is less than the $2.1 \mathrm{~kb}$ open reading frame of the full sequence eLH/CG-R, this $1.8 \mathrm{~kb}$ transcript must be an incomplete eLH/CG-R mRNA. Furthermore, it is not yet known if this $1.8 \mathrm{~kb}$ transcript encodes a functional receptor. In rats, the expression of truncated LH/CG-R mRNA transcripts is first detectable in fetal ovaries and testes as early as embryonic day 13.5 (Sokka et al. 1996) but the full-length LH/CG-R mRNA appears thereafter on embryonic day 15.5 in the testis (Zhang et al. 1994) and on postnatal day 7 in the ovary (Sokka et al. 1992). While the different eLH/CG-R cDNA isoforms were observed at all stages examined in horse fetal gonads, our results do not exclude a possible change in alternative splicing of the eLH/CG-R primary transcript before day 44 and/or after day 222 of pregnancy in fetal ovaries and testes. Furthermore, the major $1.8 \mathrm{~kb}$ eLH/CG-R mRNA transcript remained 1.2 to 3 times less expressed in fetal gonads than in the dioestrous or in the primary $\mathrm{CL}$ of adult mares during early and mid-pregnancy, which would indicate that a differential regulation of the eLH/CG-R gene transcription occurs between the fetal and the adult life in the mare.

Although gene expression does not necessarily imply that transcripts are translated in proteins or that the receptors are functionally involved in signal transduction, the presence of eLH/CG-R transcripts in horse fetal gonads indicates that the eLH/CG-R, and therefore fetal pituitary eLH and/or eCG themselves, may have a physiological role in early development and steroidogenesis of gonads in this species. Fetal content of pituitary eLH has been found to be low at day 90 of pregnancy and has been shown to increase slowly between days 90 and 150 of pregnancy (Wesson \& Ginther 1980). In contrast, the fetal blood concentration of eLH measured by radioimmunoassay was highest between days 100 and 150 of pregnancy, parallel with a rapid growth of fetal gonads (Wesson \& Ginther 1980). Since plasma eLH cannot be distinguished from plasma eCG by immunological methods, the high eLH/CG level measured in fetal blood between days 100 and 150 of pregnancy could be due, in part, to the presence of eCG in the fetal circulation. Most of the increasing weight of fetal gonads results from the hyperplasia of the medullar interstitial cells, histologically similar in fetal ovaries and testes (Cole et al. 1933). These interstitial cells are analogous to luteal cells and contain all the organelles normally associated with steroid biosynthesis (Hay \& Allen 1975). Since fetal gonads also express the full-length eLH/CG-R cDNA as early as day 44 of gestation, one can hypothesize that eCG, fetal in origin, would stimulate the initial steroidogenesis of fetal gonads.

In conclusion, the presence of the full-length eLH/CG-R CDNA isoform in the primary $\mathrm{CL}$ and in fetal gonads during eCG secretion suggests that eCG may be involved in the progressive transition from a luteal to a feto-placental output of steroids during equine pregnancy.

\section{Acknowledgements}

The authors wish to thank Guy Duchamp for his technical assistance and Peter F Daels for supplies of some fetal and 
luteal specimens. M S-D was supported by a fellowship from the Institut National de la Recherche Agronomique and the Région Centre.

\section{References}

Bergfelt DR, Pierson RA \& Ginther OJ 1989 Resurgence of the primary corpus luteum during pregnancy in the mare. Animal Reproduction Science 21 261-270.

Bousfield GR, Butnev VY, Gotschall RR, Baker VL \& Moore WT 1996 Structural features of mammalian gonadotropins. Molecular and Cellular Endocrinology 125 3-19.

Cole HH, Hart GH, Lyons WR \& Catchpole HR 1933 The development and hormonal content of fetal horse gonads. Anatomical Record 56 275-289.

Daels PF, DeMoraes JJ, Stabenfeldt GH, Hughes JP \& Lasley BL 1991 The corpus luteum: source of oestrogen during early pregnancy in the mare. Journal of Reproduction and Fertility Supplement $\mathbf{4 4}$ 501-508.

Daels PF, Albrecht BA \& Mohammed HO 1998 Equine chorionic gonadotropin regulates luteal steroidogenesis in pregnant mares. Biology of Reproduction 59 1062-1068.

Davis DP, Rozell TG, Liu X \& Segaloff DL 1997 The six N-linked carbohydrates of the lutropin/choriogonadotropin receptor are not absolutely required for correct folding, cell surface expression, hormone binding, or signal transduction. Molecular Endocrinology $11550-562$.

Ginther OJ 1992a Endocrinology of pregnancy. In Reproductive Biology of the Mare, Basic and Applied Aspects, 2nd edn, pp 419-456. Cross Plain: Equiservices.

Ginther OJ 1992b Embryology and placentation. In Reproductive Biology of the Mare, Basic and Applied Aspects, 2nd edn, pp 345-418. Cross Plains: Equiservices.

Guillou F \& Combarnous Y 1983 Purification of equine gonadotropins and comparative study of their acid-dissociation and receptor-binding specificity. Biochimica et Biophysica Acta $\mathbf{7 5 5}$ 229-236.

Hay MF \& Allen WR 1975 An ultrastructural and histochemical study of the interstitial cells in the gonads of the fetal horse. Journal of Reproduction and Fertility Supplement 23 557-561.

Holtan DW, Squires EL, Lapin DR \& Ginther OJ 1979 Effect of ovariectomy on pregnancy in mares. Journal of Reproduction and Fertility Supplement 27 457-463.

Loosfelt $\mathbf{H}$, Misrahi $M$, Atger M, Salesse R, Vu Hai-Luu Thi MT, Jolivet A, Guiochon-Mantel A, Sar S, Jallal B, Garnier J, et al. 1989 Cloning and sequencing of porcine LH-hCG receptor cDNA: variants lacking transmembrane domain. Science $\mathbf{2 4 5}$ 525-528.

Lussier JG, Houde A, Ethier J \& Silversides DW 1996 Complementary DNA structure of the bovine LH receptor. Direct submission to Genbank no U20504.

McFarland KC, Sprengel R, Phillips HS, Kohler M, Rosemblit N, Nikolics K, Segaloff DL \& Seeburg PH 1989 Lutropin-choriogonadotropin receptor: an unusual member of the $G$ protein-coupled receptor family. Science 245 494-499.

Minegishi T, Nakamura K, Takakura Y, Miyamoto K, Hasegawa $Y$, Ibuki Y \& Igarashi M 1990 Cloning and sequencing of human LH/hCG receptor cDNA. Biochemical and Biophysical Research Communications 172 1049-1054.

Pashen RL \& Allen WR 1979 The role of the fetal gonads and placenta in steroid production, maintenance of pregnancy and parturition in the mare. Journal of Reproduction and Fertility Supplement 27 499-509.

Raeside JI, Liptrap RM, McDonell WN \& Milne FJ 1979 A precursor role for DHA in a feto-placental unit for oestrogen formation in the mare. Journal of Reproduction and Fertility Supplement $\mathbf{2 7}$ 493-497.

Richard F, Martinat N, Remy JJ, Salesse R \& Combarnous Y 1997 Cloning, sequencing and in vitro functional expression of recombinant donkey follicle-stimulating hormone receptor: a new insight into the binding specificity of gonadotrophin receptors. Journal of Molecular Endocrinology 18 193-202.

Robert P, Amsellem S, Christophe S, Benifla JL, Bellet D, Koman A \& Bidart JM 1994 Cloning and sequencing of the equine testicular follitropin receptor. Biochemical and Biophysical Research Communications 201 201-207.

Saint-Dizier M, Chopineau M, Dupont J, Daels PF \& Combarnous Y 2003 Expression and binding activity of luteinizing hormone/chorionic gonadotropin receptors in the primary corpus luteum during early pregnancy in the mare. Biology of Reproduction 69 1743-1749.

Sokka T, Hamalainen T \& Huhtaniemi L 1992 Functional LH receptor appears in the neonatal rat ovary after changes in the alternative splicing pattern of the LH receptor mRNA. Endocrinology 130 1738-1740.

Sokka TA, Hamalainen TM, Kaipia A, Warren DW \& Huhtaniemi IT 1996 Development of luteinizing hormone action in the perinatal rat ovary. Biology of Reproduction 55 663-670.

Squires EL 1993 Endocrinology of pregnancy. In Equine Reproduction, pp 495-500. Eds AO McKinnon \& JL Voss. Philadelphia: Lea and Febiger.

Squires EL, Douglas RH, Steffenhagen WP \& Ginther OJ 1974 Ovarian changes during the estrous cycle and pregnancy in mares. Journal of Animal Science 38 330-338.

Stewart F \& Allen WR 1979 The binding of FSH, LH and PMSG to equine gonadal tissues. Journal of Reproduction and Fertility Supplement 27 431-440.

Stewart F \& Allen WR 1981 Biological functions and receptor binding activities of equine chorionic gonadotrophins. Journal of Reproduction and Fertility 62 527-536.

Urwin VE \& Allen WR 1982 Pituitary and chorionic gonadotrophic control of ovarian function during early pregnancy in equids. Journal of Reproduction and Fertility Supplement 32 371-381.

Vu-Hai MT, Huet JC, Echasserieau K, Bidart JM, Floiras C, Pernollet JC \& Milgrom E 2000 Posttranslational modifications of the lutropin receptor: mass spectrometric analysis. Biochemistry 39 $5509-5517$.

Wesson JA \& Ginther OJ 1980 Fetal and maternal gonads and gonadotropins in the pony. Biology of Reproduction 22 735-743.

You S, Kim H, Hsu CC, El Halawani ME \& Foster DN 2000 Three different turkey luteinizing hormone receptor (tLH-R) isoforms I: characterization of alternatively spliced tLH-R isoforms and their regulated expression in diverse tissues. Biology of Reproduction 62 $108-116$.

Zhang FP, Hamalainen T, Kaipia A, Pakarinen P \& Huhtaniemi I 1994 Ontogeny of luteinizing hormone receptor gene expression in the rat testis. Endocrinology 134 2206-2213.

Received 5 January 2004

First decision 31 March 2004

Accepted 10 May 2004 